\title{
CIÊNCIAS SOCIAIS, DIPLOMACIA E COLONIALISMO TARDIO: A PARTICIPAÇÃO PORTUGUESA NA COMISSÃO DE COOPERAÇÃO TÉCNICA NA ÁFRICA AO SUL DO SAARA (CCTA)
}

Social sciences, diplomacy and late colonialism: the Portuguese participation in the Commission for Technical Co-operation in Africa South of the Sahara (CCTA)

Ciencias sociales, diplomacia y colonialismo tardío: la participación portuguesa en la Comisión de Cooperación Técnica en África al Sur del Sahara (CCTA)

\section{FREDERICO ÁGOAS ${ }^{*}$ CLÁUdia CASTELO ${ }^{I^{*}}$}

DOI: http://dx.doi.org/10.1590/\$2178-14942019000200005

\footnotetext{
Parte da pesquisa conduzida pelo autor para a elaboração deste artigo se beneficiou de uma bolsa de pós-doutorado da Fundação para a Ciência e a Tecnologia (FCT).

I Universidade Nova de Lisboa - Lisboa, Portugal.

* Pesquisador do Centro Interdisciplinar de Ciências Sociais da Faculdade de Ciências Sociais e Humanas da Universidade Nova de Lisboa (Cics-Nova-FCSH). (fagoas@fcsh.unl.pt). ORCID iD: https://orcid.org/0000-0001-7045-7688.

Parte da pesquisa conduzida por esta autora para a elaboração deste artigo foi cofinanciada pelo Fundo Europeu de Desenvolvimento Regional (Feder), por meio do Programa Operacional Competitividade e Internacionalização (Compete) 2020, e pela FCT, no âmbito do projeto "Os mundos do (sub)desenvolvimento: processos e legados do império colonial português em perspectiva comparada (1945-1975)".

" Universidade de Coimbra (CES-UC). Coimbra, Portugal.

* Pesquisador do Centro de Estudos Sociais da Universidade de Coimbra (CES-UC). (claudiacastelo@ces.uc.pt) ORCID iD: https://orcid.org/0000-0001-7403-4404.
}

Artigo recebido em 10 de março de 2019 e aceito para publicação em 17 de junho de 2019. 


\section{RESUMO}

Instituída no segundo pós-guerra, num contexto de crescente contestação ao colonialismo e como resposta das potências coloniais europeias ao interesse científico das Nações Unidas e de círculos académicos norte-americanos pela África, a Comissão de Cooperação Técnica na África ao Sul do Saara (CCTA) revelou uma atenção particular aos estudos sociais, estabelecendo uma agenda de pesquisas paralela à da Organização das Nações Unidas para a Educação, a Ciência e a Cultura (Unesco). Com base nos arquivos diplomático e científico colonial, o artigo analisa a atividade da CCTA naquele domínio e, sobretudo, a participação portuguesa nessas dinâmicas, determinando a importância relativa do país na sua promoção e seus reflexos no campo das ciências sociais em Portugal..

PALAVRAS-CHAVE: Sociologia; Colonialismo; Portugal; CCTA; Unesco.

\section{ABSTRACT}

Established in the second post-war period, in a context of growing opposition to colonialism and as a response of the European colonial powers to the scientific interest of the United Nations and North-American academic circles in Africa, the Commission for Technical Co-operation in Africa South of the Sahara (CCTA) paid particular attention to social studies, establishing a research agenda parallel to that of the United Nations Educational, Scientific and Cultural Organization (UNESCO). Based on the diplomatic and scientific colonial archives, the article analyzes the activity of the CCTA in that domain and, above all, the Portuguese participation in these dynamics, determining the relative importance of the country in their promotion and their reflexes in the field of social sciences in Portugal.

KeYWORDS: Sociology; Colonialism; Portugal; CCTA; Unesco.

\section{RESUMEN}

En la segunda posguerra, en un contexto de creciente contestación al colonialismo y como respuesta de las potencias coloniales europeas al interés científico de las Naciones Unidas y de círculos académicos norteamericanos por África, la Comisión de Cooperación Técnica en África al Sur de Sahara (CCTA) reveló una atención particular a los estudios sociales, estableciendo una agenda de investigaciones paralela a la de la Organización de las Naciones Unidas para la Educación, la Ciencia y la Cultura (Unesco). Sobre la base de los archivos diplomáticos y científicos colonial, el artículo analiza la actividad de la CCTA en ese dominio, y sobre todo la participación portuguesa en esta dinámica, determinando la importancia relativa del país en su promoción y sus efectos en el ámbito de las ciencias sociales en Portugal.

PALABRAS ClAVE: Sociología; Colonialismo; Portugal; ACTC; Unesco. 


\section{INTRODUÇÃO}

E m Portugal, a incorporação simultânea das ciências sociais na investigação científica e no ensino superior coloniais remonta a meados da década de 1950, quando nesses domínios vigoravam ainda os estudos jurídicos e a antropologia física. Cientes da ocorrência pontual daqueles saberes em algumas instituições imperiais, ao longo da primeira metade do século XX, ou do desenvolvimento precoce da investigação social numa das ex-colônias portuguesas, a que nos referiremos adiante, queremos aqui destacar que é no decurso de apenas dois anos que são criadas as primeiras cadeiras de sociologia (1955) e de antropologia cultural (1956) no Instituto Superior de Estudos Ultramarinos (Iseu), em Lisboa, e lançadas em território africano as primeiras missões científico-sociais (1957) do Centro de Estudos Políticos e Sociais (Ceps) da Junta de Investigações do Ultramar (JIU). No primeiro caso, trata-se da instituição responsável pela formação dos funcionários administrativos do império colonial português. No segundo, trata-se de um centro de pesquisas dependente do organismo central coordenador da investigação científica nas colônias.

As missões do Ceps se ocupariam de temas como minorias étnicas do ultramar português, movimentos associativos na África, estudo da atração das grandes cidades e do bem-estar rural, entre outros. Criado em 1956 para organizar essas tarefas, o Ceps seria dirigido por um professor do Iseu, o qual passaria a assumir também a direção do próprio instituto dois anos mais tarde. Aqui, as inovações curriculares referidas ganhariam corpo com a reforma a que essa escola de quadros do Ministério do Ultramar seria submetida em 1961, passando a contar com cadeiras como metodologia das ciências sociais e sociologia da informação, ou com um seminário de investigação sociológica, para além de introdução à sociologia, que se tornava fixa - depois de ter sido incorporada como cadeira variável - e de antropologia cultural, que prosseguia no elenco. No ano seguinte, os dois movimentos culminariam na mudança do nome da escola, que passaria a se chamar Instituto Superior de Ciências Sociais e Política Ultramarina.

No que toca à pesquisa científica, em particular, essas transformações começariam por ser atribuídas à iniciativa individual de alguns dos protagonistas do processo (Pélissier, 1980: 33), para serem depois tratadas como subprodutos ideológicos da reação política dos altos quadros coloniais à transformação do contexto geopolítico após a Segunda Guerra Mundial (Gallo, 1988; Margarido, 1975). De forma mais ampla, o conjunto das inovações mencionadas seria, entretanto, reportado a uma mudança de paradigma no domínio científico em questão (Pereira, 2005) e à racionalização progressiva da administração colonial (Abrantes, 2012), na qual podem de fato ser integradas a publicação do plano de "Ocupação científica do ultramar 
português" pelo Ministério das Colônias, em 1945, e a reforma curricular da Escola Superior Colonial (designação original do Iseu), em 1946. Em outro nível, as mesmas mudanças foram ainda associadas ao crescente envolvimento dos professores do Iseu em fóruns coloniais de cooperação científica - em especial na Comissão de Cooperação Técnica na África ao Sul do Saara (CCTA), criada em 1950 pelas principais potências colonizadoras (Castelo, 2012) - e aos apelos dos quadros coloniais ativos ou em formação a respeito da sua preparação científica para governar e, no longo prazo, do seu estatuto profissional (Ágoas, 2012).

Com base nesse conjunto de pistas, que não se contradizem entre si, e assumindo a transição paradigmática referida e a racionalização gradual do aparato governativo da administração colonial (metropolitano e local), o presente artigo pretende aprofundar o estudo da participação portuguesa na CCTA e da sua importância no desenvolvimento das ciências sociais coloniais, a partir de 1950, no quadro de outras dinâmicas epistêmicas e institucionais então em curso no mesmo domínio.

À margem das referências citadas, que tratam o assunto de forma exploratória, a bibliografia sobre o tópico é praticamente inexistente. No seu livro mais recente, Valentim Alexandre (2017) aborda a iniciativa diplomática que conduziu à participação de Portugal na CCTA e o advento da investigação social portuguesa em meados da década de 1950, atribuídos aos mesmos motivos político-ideológicos e, mais especificamente, à defesa do império colonial português.

Na historiografia internacional, o organismo tem sido quase sempre ignorado ou, quando muito, apresentado como uma iniciativa duplamente falha, nos seus intentos técnicos e políticos (Kent, 1992). Não obstante, a pesquisa por nós conduzida no Arquivo Histórico Diplomático e no Arquivo da Comissão Executiva da JIU permite especificar alguns dos motivos políticos que deram corpo à CCTA - eles próprios relacionados ao avanço da investigação social na África por parte de terceiros - e avaliar a importância dos mesmos motivos e das recomendações emanadas daquele organismo no desenvolvimento das ciências sociais portuguesas no quadro da investigação colonial.

Em contrapartida, a mesma investigação permite ainda sugerir, de forma lateral, que a participação portuguesa nesse fórum, em particular no que diz respeito à cooperação em matéria de ciências sociais, assenta em iniciativas prévias de natureza análoga conduzidas de maneira relativamente precoce na antiga Guiné Portuguesa e apontar alguns efeitos epistêmicos que a cooperação internacional implicou no desenvolvimento das ciências humanas em Portugal.

De modo mais geral, o presente artigo visa ainda contribuir para discussões atualmente em curso acerca da relação entre as ciências sociais e o colonialismo tardio. Da perspectiva 
do processo de construção imperial, trata-se de perseguir a pista lançada pelo historiador Frederick Cooper (2004) a respeito do papel das ciências sociais na elaboração de políticas desenvolvimentistas dirigidas às colônias no segundo pós-guerra, com base nos casos britânico e francês. 0 caráter repressivo do desenvolvimentismo colonial português (Jerónimo, 2015) não permite analogias diretas, mas está ainda por explorar a real importância da sociologia e da antropologia no desenho das políticas coloniais durante o mesmo período. 0 presente artigo não pode corresponder a esse desígnio, mas uma investigação nessa área deverá atender necessariamente à ação da CCTA e de outras iniciativas similares. 0 mesmo se aplica quanto à obtenção de um quadro geral e definitivo sobre tal questão.

Do ponto de vista da história das ciências sociais, trata-se de assumir a proposta do sociólogo George Steinmetz (2017) para explorar o passado colonial da sociologia, na senda da já longa tradição de estudos de antropologia acerca das relações dessa disciplina com o colonialismo. Se essa última linhagem tem clara expressão em Portugal (Roque, 2001; Pereira, 2005), no caso da sociologia o tópico só foi abordado de forma preliminar e sem atender às comunidades epistêmicas internacionais de cariz colonial que cultivaram esse saber (Ágoas, 2012). Em contrapartida, a primeira tentativa de integrar o desenvolvimento histórico da disciplina em Portugal no quadro de uma história global da sociologia não faz caso da sua vertente imperial (Silva, 2016). Por fim, uma visão de conjunto da sociologia colonial europeia em meados do século XX não pode permanecer restrita aos casos britânico e francês, como até aqui, e deve integrar o caso de Portugal, tanto mais tendo em conta suas especificidades, em particular a natureza autoritária do Estado Novo português (1933-1974).

No que se segue, começaremos por relatar, na primeira seção do texto, o processo de criação da CCTA - ele próprio largamente por explorar, como dissemos - no quadro de outras iniciativas análogas e concorrentes, para sublinhar depois, na segunda seção, a importância relativa da cooperação em matéria de ciências sociais no âmbito daquela organização e 0 papel específico - e destacado, diga-se desde já - de Portugal na sua promoção. Por fim, na terceira seção recuperamos os contornos mais salientes da Conferência Interafricana de Ciências Sociais realizada em Bukavu, em 1955, como mais alta expressão da cooperação colonial nesse domínio, para dar conta das recomendações daí emanadas em matéria de pesquisa científica e relatar os ecos que tiveram em Portugal. Na conclusão, fazemos um breve balanço da participação portuguesa nesse organismo e apontamos suas consequências institucionais e epistêmicas sobre esse domínio específico, no quadro de outras iniciativas à época em curso no campo da investigação social colonial. 


\section{A COOPERAÇÃO TÉCNICA INTERAFRICANA NO PÓS-GUERRA}

C riada em 18 de janeiro de 1954, a CCTA reunia os governos de Bélgica, França, Portugal, da então recém-criada Federação da Rodésia e da Niassalândia, de Reino Unido e União da África do Sul. 0 acordo assinado em Londres formalizava a constituição e as regras de atividade da comissão, que já funcionava desde janeiro de 1950 e tinha antecedentes no imediato pós-guerra. Fruto da emergência de um "sentimento de comunidade de interesses" entre potências coloniais conscientes das ameaças externas e internas ao colonialismo (Vigier, 1954: 335), o primeiro acordo franco-britânico de cooperação na África remontava a novembro de 1945.

Ao contrário dos modelos político-administrativos e dos interesses econômicos, as questões de natureza técnica para a resolução de problemas comuns viabilizavam o entendimento entre os dois governos, que promoveriam nos anos seguintes várias conferências interterritoriais na África subsariana, nomeadamente sobre gado e medicina, e apelariam à participação de outros estados presentes na região. Esse processo de alargamento não foi isento de tensões e negociações entre os dois parceiros iniciais e no interior de cada governo. Sabe-se, por exemplo, que a inclusão de Portugal foi discutida pelos britânicos, sendo o Foreign Office favorável, pois estava interessado na manutenção de boas relações com o velho aliado, e o Colonial Office contrário, em razão do fraco desenvolvimento das colônias portuguesas e do não reconhecimento de direitos políticos e sociais às suas populações africanas (Oliveira, 2007: 67-68). Já a inclusão da Bélgica foi mais pacífica, e, em fevereiro de 1947, ocorreram conversações tripartites para a organização de conferências de cooperação técnica na África. 0 memorando das conversações anglo-franco-belgas deixa claro o objetivo não declarado publicamente: fazer face às iniciativas tomadas, em fins de 1946, pela Assembleia Geral das Nações Unidas, que previam a realização de conferências dos povos dos territórios não autônomos, bem como evitar a ingerência na gestão colonial do Comitê ad hoc então criado (Alexandre, 2017: 95). Em 1948, na conferência interafricana sobre as tripanossomíases, quase todos os países subsaarianos estiveram presentes.

Paralelamente, cientistas que trabalhavam na África, reunidos na Conferência Científica do Império organizada em 1946 pela Royal Society de Londres, também reconheceram a necessidade de estabelecer um quadro de cooperação regional. Em 1949, essa vontade conduziu à realização da Conferência Científica Africana, em Joanesburgo, com a presença de pesquisadores que desenvolviam sua atividade em quase todos os territórios subsaarianos. $\mathrm{Na}$ sequência dessa reunião e por acordo mútuo dos governos de Bélgica, França, Portugal, Reino Unido, Rodésia do Sul e União da África do Sul, nascia, em novembro de 1950, o Conselho Científico para a África ao Sul do Saara (CSA). 
O conselho se constituiria como órgão independente de aconselhamento científico da CCTA, a fim de favorecer a aplicação da ciência à solução dos problemas africanos. Seus membros eram cientistas reconhecidos, escolhidos de maneira a que as principais disciplinas científicas consideradas relevantes para o estágio de desenvolvimento da África tivessem a devida expressão, e garantindo uma representatividade geográfica dos vários países da região. Formalmente, pelo menos, os especialistas deveriam ser independentes dos respectivos governos, respondendo individualmente perante o conselho. 0 secretariado do CSA ficou instalado em Bukavu, no Congo belga. Até sua fusão com o secretariado da CCTA, em janeiro de 1955, seu secretário-geral foi Edgar Barton Worthington, zoólogo britânico que tinha colaborado com o African Survey dirigido por Lord Hailey na década de 1930. Por incumbência do secretariado conjunto, Worthington ficaria responsável pelo estudo Science in the Development of Africa, publicado em 1958.

A CCTA foi, desde o início, entendida pelos membros fundadores como uma resposta ao interesse crescente da administração norte-americana, das Organizações das Nações Unidas (ONU) e de suas agências especializadas nos aspectos técnicos do desenvolvimento da África - como a Organização das Nações Unidas para Alimentação e Agricultura (FAO), a Organização das Nações Unidas para a Educação, a Ciência e a Cultura (Unesco), a Organização Mundial da Saúde (OMS) e a Organização Internacional do Trabalho (OIT) -, assim como uma forma de as administrações coloniais se imporem como únicas e legítimas interlocutoras junto daquelas, neutralizando qualquer desafio à sua autoridade (Kent, 1992; Oliveira, 2007: 72). A promoção da cooperação técnica interafricana e a formação de uma frente unida contra as pressões anticoloniais na ONU foram, portanto, agendas interligadas (Pearson-Patel, 2015: 216). Não obstante, e apesar das críticas às suas motivações políticas (Gruhn, 1971: 459460), a CCTA não foi um organismo monolítico. As discussões internas no seio da comissão revelavam divergências entre a Grã-Bretanha e a França (Kent, 1992; Pearson-Patel, 2015). A primeira pretendia aproveitar a assistência das organizações internacionais, mantendo-a sob controle das potências soberanas na região; a segunda desejava que a CCTA fosse uma barreira institucional efetiva ao contato direto das agências da ONU com as administrações coloniais. Faltam estudos que foquem ou elucidem melhor a posição dos outros países-membros e que mostrem a CCTA na sua diversidade interna, e não apenas no confronto bilateral.

Antes de sua constituição formal, em 1954, a CCTA realizou diversas reuniões preliminares em Londres, Lisboa, Bruxelas, Cidade do Cabo e Paris. Em 1952, o secretariado permanente foi estabelecido em Londres. 0 primeiro secretário-geral foi o diplomata francês Paul-Marc Henry, a quem coube um papel de destaque no período de formação da comissão. De acordo 
com seus próprios documentos, a CCTA se assumia como um organismo intergovernamental cujo objetivo era disseminar o conhecimento científico e técnico na África subsaariana. Suas funções consistiam em promover a ação conjunta e facilitar a assistência técnica com o intuito de beneficiar todos os povos do subcontinente (CCTA, 1961:1).

Concretamente, competia-Ihe: recomendar aos governos membros medidas para alcançar essa cooperação; convocar as conferências técnicas decididas pelos governos membros; supervisionar, do ponto de vista financeiro e geral, o trabalho das organizações colocadas sob sua alçada; fazer recomendações aos governos membros para o estabelecimento de novas organizações ou a revisão de disposições existentes para a cooperação técnica no quadro da competência territorial da CCTA; fazer recomendações aos governos membros com vista à formulação de solicitações conjuntas de assistência técnica a organizações internacionais; aconselhar sobre todas as questões respeitantes à cooperação técnica que lhe fossem apresentadas pelos governos membros. Seu orçamento resultava das contribuições de cada uma das partes. Em termos de organização, a CCTA se reunia pelo menos uma vez por ano. Suas recomendações e conclusões eram submetidas aos executivos nacionais por aprovação unânime e para implementação nos territórios em causa. Gabinetes e comitês técnicos tratavam de aspectos particulares da cooperação regional e interterritorial na África subsaariana. A partir de 1955, o secretariado conjunto da CCTA e do CSA dispunha de uma sede em Londres e outra em Bukavu, sendo dirigido por um único secretário-geral, assistido ali por um secretário-geral adjunto e aqui por um secretário científico (CCTA, 1956).

Ao longo da década de 1950, e para além das sessões anuais realizadas sobretudo na Europa (Londres, 1954; Paris, 1955; Salisbury, 1956; Lisboa, 1957), a CCTA organizou diversas conferências técnico-científicas na África, sobre assuntos específicos, como condições laborais, bem-estar rural ou educação, e estabeleceu comitês regulares sobre tópicos científicos e técnicos, como cartografia, estatística, habitação, hidrologia, nutrição, entre outros. No âmbito do CCTA, foram criados gabinetes interafricanos sobre solos e economia rural, epizootias, mosca tsé-tsé e tripanossomíase, o instituto interafricano de trabalho - em competição com a OIT - e o serviço pedológico interafricano, todos com sede na África - exceto o primeiro, instalado em Paris. Estabeleceram-se ainda painéis de correspondentes em diversos domínios, como conservação da natureza, estradas ou geologia, e foram lançados projetos conjuntos, financiados por um fundo comum para a pesquisa, o primeiro dos quais o atlas climatológico da África, seguindo-se outros sobre migrações na África ocidental, absentismo e produtividade laboral, contabilidade nacional na África, controle da peste bovina, entre outros.

Em 1957, Henry deu lugar a Claude Cheysson, também indicado pelos franceses. No ano seguinte, foi criada, no âmbito da CCTA, a Fundação para a Assistência Mútua na África 
ao Sul do Saara (Fama), como instrumento de intervenção técnica. Em 1959, a sede transitou de Londres para Lagos, na Nigéria. A vaga de independências na África negra e a entrada dos novos estados independentes na CCTA tiveram como consequência a africanização da comissão, que perdeu, assim, o caráter inicial de "clube colonial" (Vigier, 1954: 349). Gana foi o primeiro estado-membro africano negro a se tornar parte da comissão (1957), seguida por Libéria (1958), Guiné (1959), Camarões (1960) e 17 outros países, em 1961.

A África do Sul, cuja política de discriminação racial e supremacia branca chocava frontalmente com os novos estados independentes, foi persuadida pelo secretário-geral Cheysson a abandonar a CCTA às vésperas da $17^{a}$ sessão, realizada em Abidjan, em 1962. A Rodésia a acompanhou. Portugal, por sua vez, viu seus delegados impedidos de participarem da sessão. Assim, ficou decidido abandonar a designação "ao sul do Saara" e convidar os países do norte do continente a se associarem, enquanto França, Bélgica e Reino Unidos passariam a membros assistentes. Cheysson pediu demissão do cargo, considerando que se devia nomear um secretário-geral africano. A passagem de testemunho para Mamoud Touré não foi fácil, dadas as rivalidades entre os vários países recém-entrados na CCTA. Em 1964, a comissão seria integrada na Organização da Unidade Africana (OUA), criada em 1963, sendo-Ihe atribuída uma nova designação: comissão científica, técnica e de investigação.

\section{O LUGAR DAS CIÊNCIAS SOCIAIS NA CCTA}

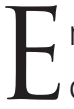
mbora a CCTA tenha coordenado atividades em diversas áreas do conhecimento, desde cedo se mostrou particularmente interessada nas ciências sociais e na promoção de estudos sobre trabalho, bem-estar rural, delinquência juvenil, habitação, migrações e educação. A vertente social de sua agenda de pesquisa deve ser entendida no contexto da crise dos impérios coloniais e de sua tentativa de relegitimação por meio de programas estatais de desenvolvimento destinados a elevar o nível de vida das populações colonizadas, bem como da internacionalização do desenvolvimento (Cooper e Packard, 1997: 7-9) e da rivalidade e competição com a Unesco.

No início da década de 1950, era já evidente que esse órgão estava empenhado no estudo das questões sociais na África. Em 1950, o departamento de ciências sociais da Unesco contatou o Instituto Internacional Africano (IAI), de Londres, para levar a cabo uma investigação sobre os efeitos sociais da industrialização naquele continente. 0 trabalho de campo, coordenado pelo diretor do IAI e professor de antropologia da Universidade de Londres Daryll Forde, se deu em Stanleyville, no Congo belga (The International African Institute, 1956). Além disso, pelo menos desde 1952, a Unesco projetava a realização de uma conferência sobre as 
consequências sociais da industrialização e da urbanização entre as populações africanas, a ter lugar na África. Franklin Frazier, sociólogo norte-americano e chefe da divisão de ciências sociais aplicadas do departamento de Ciências Sociais da Unesco, lançaria, entretanto, a convocatória da conferência que viria a ocorrer em Abidjan, entre 29 de setembro e 27 de outubro de 1954. A CCTA considerava que aquelas diligências, feitas à sua revelia, fragilizavam sua posição e pretendiam retirar crédito às suas iniciativas de cooperação entre os territórios da África subsariana.

No fim de 1952, em visita à sede da Unesco, em Paris, o secretário-geral da CCTA pôde comprovar que a agência da ONU não estava disposta a abdicar da própria agenda de pesquisa social em relação à África. ${ }^{1}$ Um ano volvido, era já claro que, além de não aceitar a exclusiva competência da CCTA na região, pretendia criar-lhe embaraços com o objetivo de destruí-la; pelo menos para o governo português, que há muito procurava convencer - sem sucesso ingleses, franceses e belgas que era impossível colaborar com a Unesco. ${ }^{2}$

É neste contexto que, em fevereiro e março de 1953, se realiza em Kampala uma primeira reunião de especialistas encarregados de planejar a investigação social na África. A proposta ali avançada de vir a criar um correspondente científico interafricano naquele domínio foi discutida na reunião de trabalho conjunta da CCTA e do CSA, em março de 1953, e na oitava sessão da CCTA, que solicitou ao CSA que formulasse uma proposta mais específica. ${ }^{3}$ Na sua quarta sessão, realizada em Tananarive, o CSA propôs que a ligação interafricana para a pesquisa social se apoiasse apenas na nomeação por cada governo membro da CCTA de um ou mais agentes de ligação e na organização de um sistema de correspondência e troca de informação por intermédio do secretariado do CSA, formando uma comissão. Entre os projetos comuns de pesquisa social a desenvolver, apontavam-se, desde logo, o estudo do crescimento da população em função dos recursos naturais e a análise dos problemas urbanos, em relação com os novos grupos sociais e sua forma de governo, ou dos diferentes modelos de cidades e vilas africanas, em função da evolução social.

No que se refere à conferência que a Unesco projetava, o conselho a considerava uma duplicação das atividades programadas pela CCTA e não mostrou qualquer abertura para uma colaboração entre as duas organizações. De fato, a CCTA só aceitaria enviar um observador. A França, que fora abordada para acolher a conferência da Unesco num dos seus territórios na África, deixou claro que só em 1954 ela poderia ocorrer. O CSA mostrava também preocupação face ao interesse na África expresso por círculos acadêmicos norte-americanos, sobretudo nos campos de antropologia e sociologia. Convidado a assistir à conferência organizada pela Universidade de Princeton sobre a pesquisa regional na África, sob os auspícios da Fundação 
Carnegie, de 14 a 16 de outubro de 1953, o secretário-geral da CCTA pôde sossegar os governos signatários relativamente à postura dos círculos acadêmicos norte-americanos. 0 movimento de curiosidade em volta dos problemas sociológicos africanos, que abrangia universidades, fundações privadas e organizações de investigação semigovernamentais norte-americanas, não punha em causa a posição da CCTA. 0 envio de pesquisadores norte-americanos para a África seria realizado em cooperação com os órgãos de investigação locais. ${ }^{4}$

Na sequência das recomendações do CSA, no fim de 1953, o secretariado da CCTA avançou com a proposta da criação de um Comitê Consultivo Permanente para a Investigação Social, a ser discutida na nona sessão. ${ }^{5}$ Face à inquietação crescente com a Unesco, do encontro sairia a recomendação urgente para a criação de um grupo de trabalho para a ligação interafricana e de projetos conjuntos em matéria de ciências sociais, que se reuniu em Londres, em 4 e 5 de março de 1954, para discutir que tipo de organização criar no domínio das ciências sociais e a eventual convocação de uma conferência sobre sociologia. ${ }^{6}$

O governo português, representado por J. M. Fragoso, secretário da embaixada de Portugal em Londres, e Adriano Moreira, professor da Escola Superior Colonial e delegado do ministério do Ultramar - em substituição a Mendes Correia, diretor daquela escola -, preconizou a criação de um Instituto Interafricano de Ciências Sociais (ou de um departamento para a sociologia), a ser instalado em Maputo, capital de Moçambique, sua colônia na costa oriental africana, dirigido por um belga. A par da proposta, a delegação portuguesa distribuiu previamente um projeto de estatutos e um memorando justificativo, no qual argumentava que só um organismo especializado seria suscetível de dotar a comissão de meios próprios para enfrentar o interesse manifestado por "entidades estranhas às responsabilidades africanas nas investigações acerca de vários aspectos das ciências sociais naquele continente" , como a OIT e, sobretudo, a Unesco. ${ }^{7}$

Portugal frisava que, ao contrário dos círculos acadêmicos norte-americanos, dispostos a solicitar a cooperação dos órgãos científicos existentes na África, a Unesco apostava em ignorar a CCTA. Além disso, a conferência planejada pela entidade das Nações Unidas abordaria "assuntos de considerável melindre e de fácil tratamento especulativo, deixa[ndo] perceber propósitos não totalmente restritos aos aspectos técnicos e científicos". ${ }^{8}$

Na ocasião, a delegação portuguesa lembrou ainda que já haviam sido recusadas pela comissão duas propostas anteriores: a criação dos departamentos de saúde e de estatística. De acordo com a posição expressa por Portugal, o primeiro teria evitado o estabelecimento da OMS na África. ${ }^{9} 0$ memorando francês, por seu turno, chamava a atenção para a intromissão de organizações americanas no continente africano e para a agenda da Unesco, propondo como medida mínima a nomeação de um correspondente científico para as ciências sociais, embora mostrasse 
abertura para aceitar a criação de um departamento de sociologia. Assim como a União da África do Sul, defendia que o correspondente fosse subordinado à CCTA, e não ao CSA, dada a incidência política dos assuntos a tratar. ${ }^{10} \mathrm{~A}$ falta de acordo final sobre a proposta portuguesa se deveu à delegação britânica, que argumentou razões financeiras - 0 instituto custaria 10 mil libras anuais -, insistindo que a CCTA não era uma organização dirigida contra qualquer outra e que deveria atuar no plano estritamente científico. ${ }^{11}$ As delegações francesa e belga acabaram por defender a criação de um órgão de cooperação de estrutura menos complexa que pudesse estar em atividade no mês de setembro, durante a realização da conferência da Unesco. ${ }^{12}$

No relatório para o ministro do Ultramar, Adriano Moreira concluía que os países representados na CCTA, e que estavam também ligados a ONU, Unesco e OIT, tinham "receio" de criar qualquer organismo que se opusesse àquelas organizações. Foi "esse o perigo que viram no Instituto que o Governo português propunha"..$^{13} \mathrm{O}$ grupo de trabalho aprovou por unanimidade a organização de uma conferência interafricana de ciências sociais e a indicação de Jacques Jérôme Pierre Maquet, antropólogo social belga do Institut pour la Recherche Scientifique en Afrique Centrale (Irsac) e especialista em Ruanda, para dirigir a comissão que deveria preparar a conferência.

O Comitê Interafricano de Ciências Sociais - ou Ciências Humanas, nos documentos em francês - foi então instituído como um organismo permanente da CCTA, destinado "a favorecer e encorajar a consulta mútua, a ligação e a cooperação no domínio das ciências sociais" na África subsaariana. Era constituído por seis membros, um por governo membro da comissão, escolhidos de preferência entre os especialistas encarregados da coordenação da investigação nos respectivos territórios. Cada governo membro estabelecia ainda a lista de especialistas e pesquisadores de cada disciplina que podiam ser chamados a participar nas deliberações do comitê (CCTA, 1955: 45-47). Na sua primeira reunião, em 1 e 2 de dezembro de 1954, o comité decidiu proceder ao inventário dos conhecimentos atuais nos diversos domínios da pesquisa relativos às ciências sociais que estão ligados ao desenvolvimento econômico da África subsaariana, tendo em vista determinar as lacunas que existem nesses conhecimentos (Henry, 1955). Os governos membros organizariam as delegações à Conferência de Ciências Sociais com base nessa tarefa prévia.

\section{A CONFERÊNCIA INTERAFRICANA DE CIÊNCIAS SOCIAIS}

omo afirmamos na Introdução, a Conferência Interafricana de Ciências Sociais pode ser considerada a mais alta expressão da cooperação científica nesse domínio, no âmbito da CCTA. 0 encontro ocorreu entre 23 de agosto e 3 de Setembro de 1955, em Bukavu, no 
território do Congo belga, associando um intenso programa acadêmico a uma agenda social preenchida. ${ }^{14}$ Os trabalhos seriam dirigidos por uma comissão liderada pelo chefe da delegação local, Frans M. Olbrechts, diretor do Museu Real da colônia, e copresidida pelos chefes das comitivas francesa e britânica, Hubert Deschamps, responsável pelo setor de ciências humanas no Office de la Recherche Scientifique Outre-Mer, e Audrey I. Richards, diretora do East African Institute of Social Research. Da mesma comissão, fizeram ainda parte António Mendes Correia, como chefe da delegação portuguesa, seus homólogos estrangeiros e os seis presidentes das várias seções da reunião.

No seu conjunto, as divisões instituídas davam corpo a uma concepção bastante eclética de ciências sociais e humanas, contemplando disciplinas ou áreas científicas tão distintas quanto demografia, geografia humana e economia política (secção I); etnologia, sociologia e etno-história (II); antropologia física, psicologia e nutrição (III); linguística (IV); métodos de administração (V); artes e tecnologia (VI). Entre os respectivos presidentes, importa destacar Adriano Moreira à cabeça da seção V. Além dos restantes delegados, estivaram ainda presentes, na qualidade de observadores, figuras como Daryll Forde, diretor do Instituto Internacional Africano, como vimos; Pierre Gourou, professor da Universidade Livre de Bruxelas e observador da Academia Real de Ciências Coloniais; Melville Herskovits, professor de antropologia da Northwestern University; Jean P. Lebeuf, chefe da seção de sociologia da OMS; Guy de Lacharrière, diretor adjunto do Departamento de Ciências Sociais da Unesco; e Prudence Smith, jornalista da BBC (CCTA, 1955: V-XI).

Com os documentos de que dispomos, não é possível recuperar em detalhe o andamento dos trabalhos, mas o inventário científico elaborado para o efeito pela comitiva portuguesa e o documento final publicado pela CCTA nos permitem especificar, como pretendemos, as orientações que serviram de base para as intervenções dos delegados portugueses e as recomendações saídas do encontro.

Quanto àquele inventário, importa começar por referir, sem surpresa - no contexto da investigação colonial portuguesa -, o desenvolvimento relativo e o caráter sistemático do relatório referente à seção III, em particular no que concerne aos estudos de antropologia física. Da mesma forma, cabe sublinhar o detalhe desproporcionado da exposição respeitante ao estudo das artes tradicionais em Angola, tal como constava do relatório referente à seção VI. ${ }^{15}$ No primeiro, de autoria de António Mendes Correia, dava-se conta de como todos os territórios portugueses na África já haviam sido objeto de pesquisas naquele domínio e destacavam-se os contributos das missões antropológicas de Angola e Moçambique. No segundo, de autoria do biólogo António Barros Machado, avultavam as atividades do Museu do Dundo 
e do seu conservador, José Redinha, no quadro da ação cultural da Companhia de Diamantes de Angola, a que o próprio relator da exposição estava também associado, na dupla qualidade de diretor de pesquisas biológicas do museu e de conselheiro científico da diamantífera.

Em qualquer dos casos, o panorama contrastava com os resultados apresentados às outras seções da reunião, que não chegavam a disfarçar as lacunas da investigação portuguesa nas matérias correspondentes, como o próprio Mendes Correia sugerira que se fizesse numa das reuniões do comitê interministerial da CCTA, que dava acompanhamento político à participação do país nesse organismo e que reunia representantes dos ministérios do Ultramar e dos Negócios Estrangeiros. ${ }^{16}$ Seja como for, pouco havia a se fazer a esse respeito, tal era a discrepância entre os relatórios em causa e os inventários entregues por outras comitivas, de que não nos ocuparemos aqui.. ${ }^{17}$

Relativamente à seção IV (linguística), tudo parecia estar ainda por fazer, em particular a organização e a publicação de dicionários e gramáticas elementares das diversas línguas dos territórios africanos sob domínio português - isso sem prejuízo de alguns estudos de caráter parcelar referidos pelo relator da seção, Rodrigo Sá Nogueira, subdiretor do Instituto de Línguas Africanas e Orientais. ${ }^{18}$ No caso da seção I, o relatório redigido por José de Oliveira Boléo, diretor-geral de Ensino do Ministério do Ultramar, era quase omisso a respeito da geografia humana, substituía o inventário de estudos de economia política pela exposição das orientações vigentes no âmbito da política econômica colonial e, no que toca à demografia, pouco mais apontava do que as perspectivas então abertas pela criação recente de um novo organismo consagrado à "demografia do ultramar" ${ }^{19}$

No que se refere à etnologia e à sociologia, em concreto, o cenário não era muito diferente. 0 relatório da seção II, que também incluía a etno-história, começava por referir, para Angola, a publicação de alguns artigos assinados por um funcionário administrativo, Mário Milheiros, e os trabalhos etnográficos do espiritano francês Charles Estermann. Para Moçambique, referia-se um artigo apenas, de Mário Simões Alberto, publicado em 1953.20 Nesse domínio, como aliás em linguística e em demografia, a exceção (parcial, pelo menos) era Guiné, em relação a qual se afirmava que "todas as tribos foram estudadas dos pontos de vista etnológico e sociológico".

O fato ficava a dever-se à ação do Centro de Estudos da Guiné Portuguesa, criado em 1945 pelo governador da colônia, Manuel Sarmento Rodrigues, e cujo grande impulsionador começara por ser o próprio relator da seção, o oficial de Marinha Avelino Teixeira da Mota. Na sua exposição, pouco se acrescentava a respeito das atividades desse organismo, mas nem por isso se deixava de fixar um programa preliminar para a investigação social no território. 
"Importa agora desenvolver estes conhecimentos de ordem geral, a partir de bases menos empíricas, considerando que o que se encontra realizado se deve em larga medida aos funcionários administrativos." Mais especificamente, tratava-se de "desenvolver os estudos de sociologia", a respeito de contatos culturais, migrações, vida urbana, níveis de vida e evolução local face às transformações econômicas. ${ }^{21}$

As orientações gerais neste domínio, todavia, ficariam a cargo de Adriano Moreira, na qualidade de relator da seção $V$, consagrada aos métodos de administração. Na sua exposição, o futuro diretor do Ceps e do Iseu começava por assinalar o desenvolvimento dos estudos concernentes à questão político-administrativa para apontar depois baterias aos tópicos da mão de obra e da destribalização, "um problema de ordem política da mais alta importância e ao mesmo tempo um fenômeno de ordem social muito interessante" sobre o qual considerava necessário intensificar os estudos sociológicos. Destacavam-se ainda os problemas da posição do posto administrativo no quadro da vida tribal e da regulamentação das migrações, por conta das suas consequências sobre a nacionalidade dos indígenas e como veículo de ideias subversivas. ${ }^{22}$

Quanto às recomendações que resultaram da conferência, reportavam-se essencialmente à instituição de práticas de cooperação e à definição de tópicos de pesquisa. Acerca da sociologia e da etnografia, assinale-se o incentivo à execução de monografias de grupos específicos - selecionados em função da representatividade regional -, o estímulo à realização de estudos sobre migrações interterritoriais - precedidos por inquéritos antropológicos nas regiões de origem - e o incitamento à troca de informações sobre os métodos utilizados na África para a aplicação de inquéritos urbanos (CCTA, 1955: 11-16).

Em termos institucionais, chamava-se a atenção para a necessidade de criar um corpo de especialistas que pudesse suprir os objetivos dos governos em matéria de pesquisa científico-social e recomendava-se que as autoridades nacionais aumentassem os apoios financeiros concedidos às instituições responsáveis pela formação nesse domínio (CCTA, 1955: 14). Em contrapartida, a seção de métodos de administração sugeria que se criasse uma "ligação permanente e estreita" entre os investigadores das ciências humanas, por um lado, e os governos e as administrações responsáveis pela acção social, por outro, "de maneira a sugerir as pesquisas destinadas à solução de problemas urgentes e práticos" (CCTA, 1955: 33).

Na mesma seção, a sociologia ou a antropologia se viam ainda potencialmente implicadas nos estudos destinados a apurar métodos e técnicas adequados aos contatos entre a população e a administração local, nas pesquisas acerca dos regimes de propriedade, na promoção econômica e social das massas rurais e nas futuras recolhas de direito costumeiro (CCTA, 1955: 33-35). A mesma orientação seria estendida a domínios de estudo como a nutri- 
ção, no âmbito do qual se assinalava a necessidade de levar em conta os aspectos sociológicos da produtividade, para além dos biológicos e dos psicológicos (CCTA, 1955: 23).

Os ecos do encontro chegariam depressa ao conhecimento dos mais altos círculos governativos da metrópole, em Lisboa. Em 2 de dezembro de 1955, António Mendes Correia, Adriano Moreira, Rodrigo Sá Nogueira e José de Oliveira Boléo participariam de uma nova reunião do comitê interministerial da CCTA destinada a apreciar os resultados da conferência. Na qualidade de presidente da delegação portuguesa, o primeiro tomaria a palavra para dar conta do relatório que submetera previamente ao ministro do Ultramar, no qual apontava a manifesta insuficiência da "nossa capacidade investigadora". Muito havia a fazer, dizia, "[p]ara prestígio nacional e interesse de cultura e das populações". Para além da concretização urgente do diploma que criara os institutos científicos de Angola e Moçambique, instara a tutela a providenciar a formação de "numerosos investigadores em muitas disciplinas" e a aproveitá-los devidamente. Como afirmava, as carências do país nessa matéria não eram compatíveis com as responsabilidades portuguesas na África e no restante do mundo. É certo, acrescentava, que a reunião de Bukavu conseguira interpor "um dique às pretensões africanas de certas entidades como a Unesco", mas impusera o dever de encarar os problemas ali identificados "num propósito de chegar a resultados satisfatórios". 23

Era essa também a opinião de Adriano Moreira, porventura formulada em termos mais concisos: "Parece que se pretende aferir a idoneidade da ação colonial já não pela ocupação do território nem pela ocupação científica do ponto de vista das ciências da natureza, mas sim em face da ocupação científica do ponto de vista das ciências humanas." Para o professor do Iseu formado em direito, a conferência tornara evidente que, "no que respeita à África, se acentua a tendência de cometer ao sociólogo e ao antropólogo o encargo de conselheiro da administração - que na Europa cabe ao jurista". Era, pois, necessário "cuidar da formação urgente, nas nossas escolas, de um quadro de especialistas em sociologia e antropologia que possam fazer a ocupação científica dos nossos territórios no domínio das ciências sociais". O corolário do seu raciocínio se impunha de forma espontânea: "No quadro dos nossos estabelecimentos de ensino, é hoje o Instituto Superior de Estudos Ultramarinos que pode servir de base, mas remodelado, a esse objetivo." 24

Poucos meses depois, o mesmo comitê emitiria seu parecer definitivo sobre a matéria, aprovado pelas tutelas. Em face das pretensões da Unesco, em particular, e de maneira a consumar o alcance político da conferência, em geral, o documento consagrava o desígnio de dar curso às recomendações dali emanadas e apontava ao governo português, como tarefas prioritárias, a necessidade de formar um quadro de especialistas em ciências sociais, pôr em 
funcionamento os Institutos de Investigação Científica de Angola e Moçambique, remodelar o Iseu e, finalmente, proceder à criação de um Centro de Estudos Políticos. ${ }^{25}$

\section{CONCLUSÃO}

$\mathrm{O}$ s dados aqui reunidos não autorizam um balanço global da participação de Portugal na CCTA, mas, no que toca à cooperação no âmbito das ciências sociais, é possível registrar o empenho e a iniciativa das autoridades portuguesas. A esse respeito, a proposta portuguesa de criação de um instituto interafricano de ciências sociais, com sede em Maputo, não deixa de ser surpreendente, considerando as resistências da parte do Estado Novo português em relação a essa forma de conhecimento e as desconfianças do regime relativamente a esse tipo de colaboração. Seja como for, as informações recolhidas permitem especificar alguns dos motivos políticos que animaram a CCTA, relacionados com o próprio avanço da investigação social na África, por parte da Unesco e de cientistas norte-americanos, e com a intenção de lhes criar entraves.

Em outro nível, a incorporação progressiva da sociologia e da antropologia cultural no currículo do Instituto Superior de Estudos Ultramarinos, nos termos avançados na Introdução, parece de fato corresponder a orientações científicas daquela comissão e a recomendações emanadas da Conferência Interafricana de Ciências Sociais, de 1955. 0 mesmo se pode dizer dos objetos das primeiras missões científico-sociais do país na África - minorias étnicas, movimentos associativos, atração das grandes cidades e bem-estar rural - e, em parte, pelo menos, do Ceps da JUU, criado em 1956 para organizá-las.

Sem prejuízo disto, também é possível afirmar que a participação portuguesa nesse fórum e os desenvolvimentos subsequentes que assinalamos assentam em dinâmicas epistêmicas em curso, em particular no Centro de Estudos da Guiné Portuguesa, por via da integração do seu principal impulsionador na delegação àquela conferência, na qualidade de relator da seção consagrada à etnografia e à sociologia - mais desenvolvidas naquele território, à época, do que em qualquer outra colônia.

Em termos substantivos, é possível sugerir, para terminar, que a participação portuguesa nesse fórum desencadeou a academização progressiva de uma etnografia administrativa timidamente iniciada em Moçambique e desenvolvida na Guiné, acelerando a transição progressiva do estudo acadêmico, quase sempre naturalista, da diversidade étnica dos territórios portugueses na África para pesquisas relacionadas a problemas econômicos e sociais e com o contexto cultural das populações do Império. 


\section{NOTAS}

1 Portugal, Arquivo Histórico Diplomático (daqui em diante, AHD), C.E47.P07.2410. Relações com agências especializadas da ONU. Informação de serviço de Franco Nogueira (MNE), 14.11.1952.

2 AHD, C.E45.P06.2403. Sociologia - Comité Ciências Humanas. Ofício do secretário-geral da CCTA, 18.2.1954, e Apontamento de Franco Nogueira (MNE), 24.2.1954..

3 AHD, C.E45.P06.2403. Doc. CCTA (53)70, Proposal to Appoint an Inter-African Scientific Correspondent on Sociology.

4 AHD, C.E45.P06.2403. CCTA - Memorandum a apresentar pelo governo português ao Grupo de Trabalho sobre Sociologia, p. 2. Ver no mesmo maço, doc. CCTA (54)26, Memorandum received from the Portuguese government - Sociology, 3.3.1954. Portugal, Universidade de Lisboa, Arquivo do Instituto de Investigação Científica Tropical, JIU, Processo 532A (CCTA - Sociologia, Economia etc.) (daqui em diante, AllCT, Proc. 532A), v. 1, Doc. CCTA (53)76, Conférence de I'Université de Princeton sur la Recherche Régionale en Afrique.

5 AHD, C.E45.P06.2403. Doc. CCTA (53)70, Proposal to Appoint an Inter-African Scientific Correspondent on Sociology.

6 AHD, C.E45.P06.2403. Ofício do secretário-geral da CCTA, 18.2.1954.

7 AHD, C.E45.P06.2403. CCTA - Memorandum a apresentar pelo governo português ao Grupo de Trabalho sobre Sociologia, p. 1.

8 Idem, p. 2

9 AHD, C.E45.P06.2403. Ofício de Manuel Rocheta ao Embaixador de Portugal em Londres, Pedro Teotónio Pereira, 26.2.1954.

10 AHD, C.E45.P06.2403. Doc. CCTA (54)24, Memorandum du Gouvernment français sur la Sociologie (Groupe du Travail du 4 mars), 1.3.1954.

11 AHD, C.E45.P06.2403. Relatório de Adriano Moreira sobre a reunião do Grupo de Trabalho realizada em Londres, em 4 e 5 de março, enviado ao ministro do Ultramar, 8.3.1954.

12 AHD, C.E45.P06.2403. Relatório do secretário da embaixada de Portugal em Londres, Fortunato de Almeida, de 5 de marco de 1955, sobre a reunião do Grupo de Trabalho sobre a ligação interafricana em matéria de sociologia, 5.3.1955.

13 AHD, C.E45.P06.2403. Relatório de Adriano Moreira sobre a reunião do Grupo de Trabalho realizada em Londres, em 4 e 5 de março, enviado ao ministro do Ultramar, 8.3.1954.

14 AHD, C.E46.P02.2436. CCTA - Documentos relativos à $1^{\text {a }}$ Conferência de Ciências Sociais, Bukavu, 1955. Programme de la Conférence Interafricaine pour les Sciences Humaines - 1ère Session, 3.06.1955.

15 AHD, C.E46.P02.2436. Conférence Interafricaine sur les sciences humaines, Bukavu, Aout-Septembre 1955, Rapport présenté par la délégation portugaise. Section III e Section VI.

16 AHD, C.E46.P02.2436. Ata da 5a Reunião Interministerial da CCTA, 27 de julho de 1955, p. 1.

17 Cf. inventários em C.E46.P02.2436.

18 AHD, C.E46.P02.2436. Rapport présenté par la délégation portugaise, Section IV. 
19 Idem, Section I.

20 Idem, Section II.

21 Idem, Section II, p. 2.

22 Idem, Section V.

23 AHD, C.E46.P02.2436. Ata da 12a Reunião Interministerial da CCTA, 2 de dezembro de 1955, p. 1.

24 Idem, p. 3.

25 AllCT, Proc. 532A, vol. 2, doc. 184. Conclusões finais do Comité Interministerial da CCTA sobre as recomendações aprovadas na $1^{\text {a }}$ sessão da Conferência Interafricana de Ciências Sociais, em anexo ao ofício da direção-geral de Administração Política e Civil do Ministério do Ultramar para a Comissão Executiva da JIU, de 23 de abril de 1956.

\section{REFERÊNCIAS BIBLIOGRÁFICAS}

ABRANTES, Carla. "Problemas" e "soluções" para a gestão de Angola: um estudo a partir do ensino superior de administração colonial em Lisboa (1950-1960). Tese (Doutorado em História) - Universidade Federal Fluminense, Niterói, 2012.

ÁGOAS, Frederico. Estado, universidade e ciências sociais: a introdução da sociologia na Escola Superior Colonial. In: JERÓNIMO, Miguel Bandeira (org.). O Império Colonial em questão (sécs. XIX-XX): poderes, saberes e instituições. Lisboa: Edições 70, 2012.

ALEXANDRE, Valentim. Contra o vento: Portugal, o Império e a maré anticolonial (1945-1960). Lisboa: Temas e Debates, 2017.

CASTELO, Cláudia. Investigação científica e política colonial portuguesa: evolução e articulações, 1936-1974. História, Ciências, Saúde - Manguinhos, v. 19, n. 2, 2012.

CCTA. Sciences Humaines. Conférence Interafricaine. 1ère Réunion. Bukavu 1955. Londres: CCTA, 1955.

COOPER, Frederick. Development, modernization, and the social sciences in the era of decolonization: the examples of British and French Africa. Revue d'Histoire des Sciences Humaines, n. 10, 2004.

COOPER, Fredrick; PACKARD, Randall (eds.). International development and the social sciences: essays on the History and Politics of Knowledge. Berkeley: University of California Press, 1997.

GALLO, Donato. Antropologia e colonialismo: o saber português. Lisboa: Heptágono, 1988.

GRUHN, Isebill. Commission for Technical Co-operation in Africa, 1950-65. The Journal of Modern African Studies, v. 9, n. 3, 1971.

HENRY, Paul-Marc. Introduction. In: CCTA/CSA. Cooperation Scientifique et Technique em Afrique au Sud du Sahara, 1948-1955. Londres: CCTA/CSA, 1955.

INTERNATIONAL AFRICAN INSTITUTE. Social implications of industrialization and urbanization in Africa South of the Sahara. Paris: Unesco, 1956. 
JERÓNIMO, Miguel Bandeira. A modernizing empire? Politics, culture and economy in Portuguese late colonialism". In: JERÓNIMO, Miguel Bandeira; PINTO, António Costa (eds.). The Ends of European Colonial Empires. Nova York: Palgrave MacMillan, 2015.

KENT, John. The creation and development of the CCTA, 1950-1956. In: KENT, John. The internationalization of colonialism: Britain, France, and Black Africa, 1939-1956. Oxford: Clarendon Press/ Nova York: Oxford University Press, 1992.

MARGARIDO, Alfredo. Le colonialisme portugais et I'anthropologie. In: COPANS, Jean (ed.). Anthropologie et impérialisme. Paris: François Maspero, 1975.

OLIVEIRA, Pedro Aires. Os despojos da aliança: a Grã-bretanha e a questão colonial portuguesa (1945-1975). Lisboa: Tinta-da-China, 2007.

PEARSON-PATEL, Jessica. Promoting Health, Protecting Empire: Inter-Colonial Medical Cooperation in Postwar Africa. Monde(s), v. 7, n. 1, 2015.

PÉLISSIER, René. L'Afrique portugaise dans les publications de la Junta de Investigações do Ultramar (Lisbonne). In: PÉLISSIER, René. Africana: bibliographies sur I'Afrique luso-hispanophone. Orgeval: Éditions Pélissier, 1980.

PEREIRA, Rui. Conhecer para dominar: o desenvolvimento do conhecimento antropológico na Política Colonial portuguesa em Moçambique (1926-1959). Tese (Doutorado em Antropologia) - Universidade Nova de Lisboa, Lisboa, 2005.

ROQUE, Ricardo. Antropologia e Império: Fonseca Cardoso e a expedição à Índia em 1895. Lisboa: Imprensa de Ciências Sociais, 2001.

SILVA, Felipe Carreira da. Sociology in Portugal: a Short History. Basingstoke: Palgrave Macmillan, 2016.

STEINMETZ, George. Sociology and Colonialism in the British and French Empires, 1945-1965. The Journal of Modern History, v. 89, n. 3, 2017.

VIGIER, Daniel. La Commission de coopération technique en Afrique au Sud du Sahara, Politique étrangère, n. 3, 1954. 